\title{
Social Skills Amongst MMORPG-Gamers: Empirical Study
}

\author{
Olga Sergeyeva ${ }^{1,2, *}$, Anna Tsareva $^{1}$, Nadezhda Zinoveva $^{2}$ and Olga Kononova ${ }^{3}$ \\ ${ }^{1}$ St Petersburg University, Faculty of Sociology, 1/3, entrance 9, Ul. Smolnogo, St.Petersburg, Russia \\ ${ }^{2}$ SI RAS - FCTAS RAS, 190005, 7-ya Krasnoarmeyskaya str. 25/14, St. Petersburg, Russia \\ ${ }^{3}$ ITMO University, Institute of Design \& Urban Studies, 197101, 49 Kronverkskiy pr, St. Petersburg, Russia
}

\begin{abstract}
The research paper addresses the issue of the impact of MMORPGs on social culture and communication skills of individuals. The mainstream discourse about computer games which take individuals away from reality and substitute the real life by the fictional one is complemented by brand new ideas, which affirm that computer games do not substitute but supplement the real life and expand its possibilities. To confirm the presented point of view we use diagnostic questionnaire of interpersonal relations by A.A. Rukavishnikov. This questionnaire is aimed to evaluate typical ways of respondent's attitude towards other people. At this point we have 43 gamers and 29 nongamers involved in our research, aged 18 to 57. The comparison of a user and non-user answers gives a bigger view on an overall gaming experience. In the obtained indices we note that there are no fundamental differences between MMORPGs gamers and ordinary people. During research, MMORPGs users have showed many important social interaction skills such as striving to control own actions, collaborate with others, though with a low interest in emotionally charged relationships. Authors discuss the idea about the differences between addiction and fascination among gamers.
\end{abstract}

\section{Introduction}

Over a decade computer games have been a part of our daily life through portable, non-portable and handheld devices, ever-evolving and inevitably changing our experience. This research focuses on individual communication traits and habits among the users of Massive Multiplayer Online Role-playing Games (MMORPG).

The current discourse, as opposed to an argument that computer gaming isolates people and takes away from their real lives, accumulates new ideas that computer games enrich an everyday experience, enhancing its potential and possibilities. Participating in MMORPG, in authors' opinion, plays a socializing role. Socialization effect stimulated by computer games overreaches gaming environment as well as spreads onto a real-life experience. The need for interaction in MMORPG pushes gamers to attain and develop such skills as leadership, decision-making, responsibility and teamwork. Gaming acts as a practice tool allowing for betterment of social interaction skills. Absence of offline life social limits and fear of failure plays a great role in quicker learning. Research of social competence skills among gamers and non-gaming participants can reveal the answer to: does gaming experience alter and override real life or enrich it? This paper presents the results of competence testing among active gamers

\section{Literature overview}

When first massive multiplayer online games appeared, they were considered and studied as common single player games (offline). The following aspects were considered: escapism and avoidance of taking roles in the social environment, the desire of a gamer to get rid of the problems associated with everyday life through withdrawal to the fictional world of the game. Target group of those researches were mostly teenagers. MMORPG researchers studied the reasons of computer game addiction, "ludomania" (Yee [1], Lo and others [2], in Russia - Ivanov [3], Lozgacheva [4], Kozlova and Tchukhrova [5] and others). Online gamers asocial, aggressive and deviant behavior was regarded (Andersen [6], Yee [7], Kuznetsova [8]) alongside the reasons of interest towards MMORPGs connected to frustration, social phobia, depression and loneliness (Wei [9], Bragina [10]). Such types of research are being done nowadays.

The expansion of the Internet into everyday life changed the notion of space and time, formed a new experience - where different spaces are combined (simultaneity of space), and time is accelerating and synchronizing. Multiplayer games have also changed: there have been introduced diverse ways of economical involvement (trading in-game bonuses for real money), social activities to achieve gaming goals, that give rise to

* Corresponding author: o.v.sergeeva@spbu.ru 
interpersonal relations for participants. MMORPG, in this way, models many types of human practice. The age structure of the gamers has also changed, MMORPGs are no longer fun for only kids, but also is favored by adults.

For the past 10 years, a lot of research have been conducted relating to Russian and international gamers and this has revealed both destructive and constructive effects caused by multiplayer online video games. The social aspect of the game is pointed out and it becomes more relevant due to necessity to make gaming social groups to achieve common goals. As Pozharov puts it, that could mean "to belong to the group; to compete with other similar groups; constructing responsibilities before the group (attending the event at the appointed time, performing the tasks correctly and etc.); communication skills mastering in conditions of hierarchical or equal structure and ability to obey or give orders" [11, P. 272]. According to the studies the pleasure of social effects such as friendship or belonging - becomes as important as the outcome of completing in-game tasks for the gamers [12]. Moreover, researchers also noted that MMORPGs promote social activity of gamers to form friendly and romance relations with their in-game squadmates, participating in MMORPG with members of their families or real-life friends (Cole, Griffiths [13], Frank and others [14], Bragina [15]), active life position and the ability to overcome in-game difficulties and work in a team (Zhong [16]); prominent gamers' social skills improvement (Griffiths [17], Savinskaya, Shotashvili [18]).

Today we can apply to the data from generational research aimed at specific groups, whose socialization was established during mass distribution of video games. According to Beck and Wade [19], the current "gamer generation" has some advantages over their parents. The authors conclude that the worlds created by the video games establish learning situations that prepare gamers for the real institutions.

Thereby the research view about the multiplayer online games have changed over the time due to the social and technical changes (the Internet popularizing, the miniaturization of digital technology), and the new interactive game mechanics creation. Increasingly, the focus of attention is directed to the MMORPGs function as interest clubs that unite gamers not only in virtual space but also outside for friendly and other social communications.

\section{Method}

\subsection{Specificity of the test}

The interest in the personal qualities of the MMORPG gamers (namely, social competence) led us to measure them by testing. Avanesov, the author of treatise about the tests application in sociology, writes: "if in a sociological study there is a need to assess the relationship of the personal qualities of respondents with their acts, deeds ..., then for this purpose some tests that psychologists have can be used" [20, P. 38].

It was important for us to understand what types of personality are common among those who regularly practice multiplayer online role-playing games. Wanting to check whether the experience of the game is associated with any specific qualities of the personality, manifested, above all, in the interaction, we turned to the testing procedures.

The diagnostic questionnaire of interpersonal relations by A.A.Rukavishnikov is aimed to evaluate typical ways of a respondent's attitude towards other people in our research. This test is an adaptation of FIRO (Fundamental Interpersonal Relations Orientation) questionnaire, quite popular in foreign scientific practice, developed by American psychologist Schutz [21]. The core idea behind the questionnaire is that all people develop a strategy of relations with the social world, and this strategy determines their behavior in interpersonal interactions. The questionnaire is a tool for identifying three major areas of interpersonal needs: Inclusion (I), Control (C) and Affection (A). Each of these areas is viewed in two aspects: expressed behavior of the individual and wanted behavior.

Need for Inclusion (I) is an ambition and a skill to establish and maintain relationships satisfactory to the individual with others. Need for Control (C) regards an ambition to establish and maintain satisfactory relations with other people based on authority. Need for Affection (A) is seen as the need to establish and maintain satisfactory relationships with others relying on emotional relationships.

Overall there are 54 statements in the questionnaire for a respondent to choose one of answers specified by a six-point scale. Our test-questionnaire is also enhanced with the questions about the respondents gaming experience: how long they play, what kind of games they play and how often, as well as social and demographic data. The non-gamers have also been involved in testing in order to compare the social competencies of those who were keen and not carried away by games.

\subsection{Data collection and processing}

Testing the gamers older than 18 years old who play MMORPGs at least once a week was conducted from the summer of 2016 to the beginning of 2017. The test questions were posted to Google Groups.

To distribute the link to the test, a volunteer playing in "Travian" was found, who involved other gamers to testing using the "snowball" method. The sample is purposeful, as the testing was done by the people who meet a number of parameters - only adults who often play in MMORPGs. The questionnaire was also distributed among adults who do not play any computer games at all. As a result, 43 gamers and 29 non-gamers have passed the testing. The data were processed using Excel. The data obtained were analyzed in two sections: a common array of data to identify predispositions in a group of gamers (when compared with non-gamers) and individual profiles of the respondents. 


\section{Results}

Depending on how often a person plays, subjects can be divided into two groups: 1) playing daily (28 people), 2) playing at least once a week (15 people). The gaming experience of respondents is from 1 to 20 years including all kinds of video games not only MMORPGs. Among the most favored online games the participants most frequently called out "The World of Warcraft", "Travian", "DoTa2", "The World of Tanks", "Lineage 2", "League of Legends".

The majority of gamers have higher or incomplete higher education $(65 \%)$, the others study at university $(12 \%)$ or have received a secondary special education $(23 \%)$. The non-gamers mostly have higher education (79\%) and $21 \%$ have secondary special education. There are people of different professions and spheres of employment, among them there is a geologist, lawyer, manager, builder, engineer, system administrator, freelancer, psychotherapist, nurse, cutter, accountant, economist, civil servant, shop assistant, etc.

The average age of the gamers is 33 years old; the average age of non-gamers ones is 35 years old.

To clarify the typical average orientation of group inclusiveness, the ambition to control and support emotional contacts, we calculate standard deviations and create a portrait of an "average gamer" by calculating the average values for each of the six scales (Ie, Iw, Ce, Cw, Ae, Aw). The "average gamer" who's participated in the test has the following distinctive orientations in social behavior:

Table 1. Average gamer.

\begin{tabular}{|c|c|c|c|c|c|c|}
\hline & \multicolumn{2}{|c|}{$\begin{array}{c}\text { Group } \\
\text { inclusiveness } \\
\text { ambition }\end{array}$} & \multicolumn{2}{|c|}{$\begin{array}{c}\text { Ambition to } \\
\text { control vs to } \\
\text { be } \\
\text { controlled }\end{array}$} & \multicolumn{2}{|c|}{$\begin{array}{c}\text { Ambition to } \\
\text { support } \\
\text { emotional } \\
\text { contacts }\end{array}$} \\
\hline & Ie & Iw & $\mathrm{Ce}$ & $\mathrm{Cw}$ & $\mathrm{Ae}$ & $\mathrm{Aw}$ \\
\hline Mean & 4.3 & 4.8 & 5.3 & 3.8 & 3.3 & 4 \\
\hline $\begin{array}{c}\text { Standard } \\
\text { Deviation }\end{array}$ & 1.8 & 2.9 & 2.4 & 2.1 & 1.6 & 2.1 \\
\hline
\end{tabular}

As the Table 1 results show, the values of mean deviations are small, only Iw demonstrates slightly higher violation. This allows us to conclude that gamers' scores are characterized by low variability and the average score correctly represents the respondents' data. We also compare the average points of gamers with the points of non-gamers, here the standard deviation does not exceed 2,1 .

The average scores on all scales for MMORPG gamers and non-gamers show either a transitional score from low to high (4-5) or a low score (close to 3). Amongst all there are slightly higher points for Ambition to control others and take leadership (for gamers $\mathrm{Ce}=$ 5.3, for non-gamers $\mathrm{Ce}=5.8$ ). In this case, both the average gamer and the non-gamer show the low need for more emotional relations with other people (for gamers $\mathrm{Ae}=3.3$, for non-gamers $\mathrm{Ae}=3.4$ ).
Table 2. Average non-gamer.

\begin{tabular}{|c|c|c|c|c|c|c|}
\hline & \multicolumn{2}{|c|}{$\begin{array}{c}\text { Group } \\
\text { inclusiveness } \\
\text { ambition }\end{array}$} & \multicolumn{2}{|c|}{$\begin{array}{c}\text { Ambition to } \\
\text { control vs to } \\
\text { be } \\
\text { controlled }\end{array}$} & \multicolumn{2}{|c|}{$\begin{array}{c}\text { Ambition to } \\
\text { support } \\
\text { emotional } \\
\text { contacts }\end{array}$} \\
\hline Mean & 3.9 & 3.9 & 5.8 & 4.3 & 3.4 & 3.7 \\
\hline $\begin{array}{c}\text { Standard } \\
\text { Deviation }\end{array}$ & 1.3 & 2.1 & 1.34 & 2 & 1.7 & 1.9 \\
\hline
\end{tabular}

The value presented in Table 3 and called the index of the volume of interactions reflects the intensity of interactions, interpersonal contacts, control actions and need for inclusion in the group, preferred by the average gamer and the average non-gamer. This index is calculated as $\mathrm{e}+\mathrm{W}$ and can vary from 0 to 18 . In the obtained indices we note that there are no fundamental differences between MMORPGs gamers and ordinary people.

Table 3. Index of interactions of average gamer and average non-gamer.

\begin{tabular}{|c|c|c|c|}
\hline & $\begin{array}{c}\mathrm{I}(\mathrm{e}+\mathrm{W}) \\
\text { Group } \\
\text { inclusiveness } \\
\text { ambition }\end{array}$ & $\begin{array}{c}\mathrm{C}(\mathrm{e}+\mathrm{W}) \\
\text { Ambition to } \\
\text { control vs to } \\
\text { be } \\
\text { controlled }\end{array}$ & $\begin{array}{c}\mathrm{A}(\mathrm{e}+\mathrm{W}) \\
\text { Ambition to } \\
\text { support } \\
\text { emotional } \\
\text { contacts }\end{array}$ \\
\hline Gamer & 9.1 & 9.1 & 7.3 \\
\hline $\begin{array}{c}\text { Non- } \\
\text { gamer }\end{array}$ & 7.8 & 9.1 & 7.1 \\
\hline
\end{tabular}

In addition to the index of the volume of interactions our test data allows us to estimate the index of the contradictory nature of interpersonal behavior. This index qualifies the gap between the one's evaluation of their own behavior and their demands to the behavior of others. The value of the index can vary from 0 to 9 . The closer is the value of the index to 9, the greater is the gap and the probability of dissatisfaction of different social aspirations. However, in our case, Table 4 shows the balance of the behavior of both gamers and non-gamers while the indices of both tested groups are practically identical.

Table 4. Index of contradictory nature of interpersonal behavior of average gamer and average non-gamer.

\begin{tabular}{|c|c|c|c|}
\hline & $\begin{array}{c}\text { I (e - W) } \\
\text { ambition to } \\
\text { group } \\
\text { inclusiveness } \\
\text { and to expect } \\
\text { the same from } \\
\text { others }\end{array}$ & $\begin{array}{c}\mathrm{C}(\mathrm{e}-\mathrm{W}) \\
\text { Ambition to } \\
\text { control vs to } \\
\text { be } \\
\text { controlled } \\
\text { and to } \\
\text { expect the } \\
\text { same from } \\
\text { others }\end{array}$ & $\begin{array}{c}\text { A (e - W) } \\
\text { Ambition to } \\
\text { support } \\
\text { emotional } \\
\text { contacts and } \\
\text { to expect the } \\
\text { same from } \\
\text { others }\end{array}$ \\
\hline Gamer & 0.5 & 1.5 & 0.7 \\
\hline $\begin{array}{c}\text { Non- } \\
\text { gamer }\end{array}$ & 0 & 1.5 & 0.3 \\
\hline
\end{tabular}


On the basis of data about an individual gamer and a non-gamer, we have observed individual profiles of those who play daily at least two hours a day. This special attention to the often playing respondents is reasoned by the assumption of their possible a-social behavior discussed in the research literature. There are 18 often playing respondents among those who passed the test.

Table 5. Average score of gamers playing daily two or more hours.

\begin{tabular}{|c|c|c|c|c|c|c|}
\hline & \multicolumn{2}{|c|}{$\begin{array}{c}\text { Group } \\
\text { inclusiveness } \\
\text { ambition }\end{array}$} & \multicolumn{2}{|c|}{$\begin{array}{c}\text { Ambition to } \\
\text { control vs to be } \\
\text { controlled }\end{array}$} & \multicolumn{2}{|c|}{$\begin{array}{c}\text { Ambition } \\
\text { to support } \\
\text { emotional } \\
\text { contacts }\end{array}$} \\
\hline & $\mathrm{Ie}$ & $\mathrm{Iw}$ & $\mathrm{Ce}$ & $\mathrm{Cw}$ & $\mathrm{Ae}$ & $\mathrm{Aw}$ \\
\hline Mean & 4 & 4.6 & 5.2 & 4.6 & 3.7 & 4.3 \\
\hline $\begin{array}{c}\text { Standard } \\
\text { deviation }\end{array}$ & 2.2 & 2.9 & 2.7 & 2.2 & 1.5 & 2.7 \\
\hline
\end{tabular}

Gamers who spend considerable time on MMORPGs do not possess prominent communicative qualities (see Table 5). 7 of them are married, two have the position of a manager, one is a businessman. Managers and a businessman have demonstrated the aspiring behavior in the field of control and tend to take responsibility in the group $(\mathrm{Ce}=8)$.

\section{Discussion}

The testing method made it possible to identify the social competencies of MMORPGs gamers and to compare them with the properties of non-gamers. Explaining the absence of any extreme points characterizing the social competencies of gamers, we refer to the MMORPGs specific. It should be noted that in the context of MMORPGs certain interaction skills are supported and they aim to the joint in-game tasks implementation, the formation of common experience and the creation of interaction networks with other game participants. MMORPG is a communicative space with socializing capabilities and resources for accumulating the social capital of gamers, although the features of these communications arise from game mechanics. The various games software forms opportunities and limitations for gamers to communicate, to establish group relations and to perform shared organized actions.

To reveal the MMORPGs specific compared to other computer games, we distinguish two types of games conventionally called "the active involvement games" (they have an external locus of control) and "the initiative involvement games" (they have an internal locus of control). This typology allows us to see such important characteristics of game communication as the strict rules of gaming interaction, the active or passive identifying the game goals and game actions focusing, the possible initiative and creativity to realize the game tasks, orientation to you or to other gamers and etc.

"Active involvement games". This game type engages a set of incentives that constantly motivate a gamer to continue playing. These are, for example, arcade-style games, shooters and action games. "Initiative involvement games". In the games of this type the incentives for playing are not directly objective, but symbolic. The activity in the fancied place makes a gamer learn to follow not only the immediate perception of any situation or thing whereas to keep in mind the sense of the given situation. The basic interest of a gamer is aimed at interpreting what is happening around, at the cooperation with other gamers in the game process and the creative constructing of the game world. The games of this type are text multiplayer game worlds, network simulators, strategic action games, role-playing games (MMORPGs).

Games of active and initiative involvement, therefore, represent two qualitatively different ways of constructing the social and psychological experience of gamers. These are various forms of initiative, decisionmaking, conditions and goals for individual and group activity, interest in cooperation. One of the main factors of MMORPG attraction is the possibility to play with other people in real time, to carry out real interaction within the virtual game world and to implement the relations of competition, cooperation and to achieve goals in a computer-mediated environment. Many of these games are based on the principles to capture and retain a territory when one person cannot achieve any result and the win depends on the team unity and spirit. That encourages gamers to join into permanent teams ("clans") and to build a successful communication within the team. Gamers have to negotiate effectively, to act coherently, to lead, to take responsibility, to contribute to the common victory. Important in such games are the capabilities of strategic thinking, helping to build common actions that lead the team to win. The ability to talk during the gaming session reinforces the team connections. Therefore, the gamers participating in this study whose game experience is associated with the active involvement games do not demonstrate social exclusion, they are oriented to group interactions.

When it comes to computer games and gamers we agree with the Moscow sociologists Savinskaya and Shotashvili [19] idea about the differences between addiction and fascination. Preoccupation with game and spent time period characterize an enthusiastic and interested person but not the one who is only dependent or lost control. Moreover, today computer games are mobile, the transition to game does not require some special time, but computer games can be played at those time intervals that previously had to be spent without activity, for example, a journey, a queue, etc.

\section{Conclusion}

Modern MMORPGs represent a public space where social competence of its participating gamers is in demand. An average gamer's communication image can be developed on testing the interpersonal relations development level in users' environment. Then, comparison of a user and non-user interface gives a bigger view on an overall gaming experience. During 
research, MMORPGs users have showed many important social interaction skills such as striving to control own actions, collaborate with others, though with a low interest in emotionally charged relationships.

Leadership is common among the examinees, since many focus on themselves rather than the opponents. At the same time, when building interpersonal relationships, there is a slight prevalence of expectations and demands from others ("wanted" behavior) over readiness for one's own actions ("expressed" behavior).

Interaction through social network, such as MMORPGs allows one to support social capital, the gamers develop friendly relations in a group. Those are advantages and opportunities of belonging to a group, and a base for shared actions.

The reported study was funded by RFBR according to the research project "Scientific methods in research of computer game experience", № 16-06-00368

\section{References}

1. N. Yee, Understanding MMORPG addiction, URL : http://www.nickyee.com/hub/addiction/addiction.pd $\underline{\mathrm{f}}$ (date of access 11.04.2018)

2. S. K. Lo, C. C. Wang, W. Fang, Cyberpsychol Behav 8 (1), 15 (2005)

3. M.S. Ivanov, Psychology of addiction: Reader (Harvest, Minsk, 2004)

4. E.A. Lozgacheva, Monitoring of public opinion: economic and social changes 3 (87), 126 (2008)

5. L.I. Kozlova, M.G. Chuhrova, Mir nauki, kul'tury, obrazovaniya 3 (34), 193 (2012)

6. C. A. Anderson, K. E. Dill, Journal of personality and social psychology 78 (4), 772 (2000)

7. N. Yee, Presence (Camb) 15 (3), 309 (2006)

8. E.V.Kuznecova, Vestnik Moskovskogo universiteta MVD Rossii 10, 85 (2014)

9. H. T. Wei, et al., BMC psychiatry 12, (2012)

10. O.A. Bragina, Penza Psychological Herald 2, 77 (2015)

11. Pozharov, Historical and social-educational thought 6(6_2), 270 (2014)

12. V. A. Sublette, B. Mullan, Int J Ment Health Addict 10 (1), 3 (2012)

13. H.Cole, M. D. Griffiths, Cyberpsychol Behav 10 (4), 575 (2007)

I. Frank, N. Sanbou, K. Terashima, Proceedings of the international conference on Advances in computer entertainment technology (ACM, NY, 2006)

14. O. A. Bragina, Bulletin of the Saratov Regional Institute of Education Development 1, 94 (2015)

15. Z.-J. Zhong, Comput Human Behav 27 (6), 2352 (2011)

16. M. Griffiths, Aloma: Revista de Psicologia, Ciències de l'Educació i de l'Esport 27, 301 (2010)
J. O. B. Savinskaya, V. A. Shotashvili, Monitoring of public opinion 5 (117), 123 (2013)

K. C. Beck, M. Wade, Got Game: How the Gamer Generation is Reshaping Business Forever (Business School Press, Harvard, 2004)

17. V.S. Avanesov, Tests in sociological research (Nauka, Moskow, 1982)

18. W. Schutz, The Interpersonal Underworld (Science and Behavior Books, Palo Alto, Calif, 1966) 